\title{
Pensar el mundo, practicar el entorno. Etnografías y reflexiones desde una antropología de las territorialidades
}

\section{Thinking the World, Practicing the Social Environment: Ethnographies and Reflections from an Anthropology of Territorialities}

\author{
Beatriz Nates Cruz \\ Grupo de Investigación Territorialidades \\ Instituto de Investigaciones en Ciencias Sociales y Humanas \\ Universidad de Caldas, Colombia
}

\section{RESUMEN}

Este artículo mostrará y analizará desde una visión antropológica la configuración y las formas que toman la definición y ubicación del mundo y el entorno, tanto como posturas filosóficas, que como objetivaciones físicas y geográficas entre culturas diferentes: los indígenas y yanaconas del Macizo Colombiano, los llamados "paisas" de los Andes centrales de Colombia y los habitantes del sur de Francia y norte de España en su relación con los inmigrantes del norte de Europa. Aunque haya distancia cultural, física y social, los contenidos tendrán a menudo posturas relacionales.

Palabras clave: Mundo; Entorno; Territorio; Colombia; Francia; España.

\section{SUMMARY}

This article will anthropologically present and analyze the configurations and the forms taken by the definition and location of the world and the social environment as philosophical postulates, and as physical and geographical objectivations among different cultures: the natives and Yanaconas of the Colombian Massif, the "paisas" of the Central Colombian Andes, and the southern France and northern Spain inhabitants in their relationship with immigrants of northern Europe. Even though there is a cultural, physical and social distance, the contents will frequently have relational postures.

Key Words: World; Social environment; Territory; Colombia; France; Spain. 
En el Macizo Colombiano los campesinos e indígenas yanaconas ${ }^{1}$ conciben el mundo como "lo bravo", lo que está virgen, salvaje y a partir de lo cual hay que habitar, poblar, sembrar: en suma, como ellos dicen, lo que se debe "amansar". Pero también es a la vez un lugar físico y metafísico donde viven los antepasados y seres (humanos y animales que se pueden objetivar material y míticamente) "lejanos" o "extraños". De otra parte, el entorno es lo manso, lo que rodea a los humanos y lo que es asequible. Por el contrario, entre los denominados "paisas" de los Andes centrales de Colombia, el entorno está aquí y "el mundo" es lo que hay que colonizar, de lo que hay que apoderarse como forma de poder político y económico. Para ellos el entorno pasa siempre por aquello que se coloniza pero que paradójicamente "a lo lejos" siempre queda más. En el sur de Francia y en el norte de España, "los forasteros" son quienes buscan el entorno, los nativos están allí, lo ven o quizá ya no, quizá sólo lo viven. Pero los "llegados" (británicos, holandeses, alemanes, suizos...) a pueblos y pedanías buscan ese entorno perdido, buscan su naturaleza.

El entorno es uno de los conceptos quizá más ambivalentes en el estudio de la antropología de las territorialidades. Dedicar este artículo a exponer y analizar las concepciones teóricas, pero también las posiciones de pensamiento y prácticas culturales en distintas sociedades sobre este concepto, implicará cruzarlo a veces con otros como medio, ambiente (tener mundo, situación...), hábitat, contexto, naturaleza, en cuya relación radica en mucho la ambivalencia del concepto de entorno. Sin embargo, estos cruces serán siempre en el sentido de lugar, esto es, en cómo diferentes sociedades crean territorios a partir de su concepción, uso y manejo de lo que consideran "el entorno".

El contenido etnográfico de este artículo está basado en trabajos de campo que he realizado en los Andes del sur de Colombia (campesinos e indígenas yanaconas), los Andes del centro de Colombia (los paisas), el sur de Francia y el norte de España (entre nativos rurales e inmigrantes de Europa del norte, especialmente ingleses y alemanes). Estas equidistancias nos permitirán tener una gama comparativa bastante sugerente en los temas tratados.

PENSAR EL MUNDO

La idea de trabajar desde el concepto de "el mundo" para practicar o aprehender el entorno, radica en su importancia etnográfica y teórica.

\footnotetext{
${ }^{1}$ Aunque culturalmente todos se reconocen indígenas, políticamente sólo se llaman indígenas yanaconas quienes habitan en resguardos o reservas indígenas, el resto se autodenominan campesinos.
} 
Etnográficamente he encontrado en las investigaciones referenciadas una marcada diferencia entre estos dos conceptos, no ya porque se presenten y diferencien de manera explícita, sino por como se ponen en los discursos sobre sí mismos, sobre los otros, sobre lo que está lejos, lo inaprensible pero imaginable y lo que les rodea. Así, encuentro que entre los campesinos y yanaconas, "el mundo" es siempre referencia de lo bravo, a lo que se debe acceder bajo ciertas reglas, y aunque este acceso no es siempre material, sin embargo debe estar en la posibilidad de todos, así el discurso más elaborado lo manejen los "tewuas" (chamanes), los gobernadores de cabildo (gobernantes de las reservas indígenas), los maestros, dicho de otra manera, los intelectuales.

Por su parte, entre los "paisas" el mundo aparece como "el monte", "lo gringo", como he dicho antes, lo que se debe colonizar. Tan gringo es el mundo de lo que puede ser imaginado o contado por los inmigrantes como Europa, como lo mismo soñado por ellos, New York.

Entre los habitantes del sur de Francia, la idea de mundo aparece como "lo que tiene la Unión Europea", lo demás es igualmente referenciado bajo la idea de mundo (lo global), pero es de difícil aprehensión, porque se referencia para negarse: "Eso en Turquía, comen carne de perro [...] ¿se imagina cuán distantes están de nosotros?”. “Pero existen entonces los turcos?”: "Sí, pero son gentes que no nos caben en la cabeza sino para decir que están alli [...]" (entrevista de trabajo de campo 2006). En los pueblos españoles cercanos a Matavenero y Poibueno, en San Facundo o en la Torre del Bierzo, por ejemplo, los "limpios" (ecológicos), como les llaman a los inmigrantes alemanes y suizos pobladores neorrurales de esos lugares, "tienen mundo". La explicación a esto es que ellos "salen" y "entran", conocen más y, también, "han sido siempre europeos", pues muchos de los españoles entrevistados asumen que son europeos por "decreto", es decir, desde que forman parte de la Unión Europea. Pero además hablan del "mundo" cuando se refieren a los "moros" o "sudacas": "En Marruecos, eso en Venezuela y en México, eso es un mundo lejos, al otro lado del charco, pero aunque no son iguales que los moros, los sudacas sí son de otro mundo". "¿Y para qué les sirve saber de esas existencias, si son tan distintos?": "Hombre, para saber que no son como nosotros, son distintos, y sabemos también que el mundo es grande aunque sólo nos guste lo que tenemos cerca [...]" (entrevista en trabajo de campo 2006).

En esta medida, "el mundo" como concepto permite comprender de cierta manera el sentido bajo el cual se construye la dimensión social desde la que se intenta interpretar y practicar la realidad en sentido amplio. El manejo de este concepto como referente de lo "lejano" puede posibilitar la comprensión de las diversas formas en que se conciben, manejan y 
transforman los ordenamientos simbólicos y las acciones de la vida cotidiana.

Pensemos entonces en la expresión "el mundo me cabe en la cabeza", a eso me refiero; es decir, a que de manera intelectual o física por conocimiento directo o por referencias a través de distintos medios sabemos de otras culturas, de otros lugares. Sin embargo, los occidentales o quienes como mestizos hemos sido educados según las maneras de Occidente, pensamos a menudo, o casi siempre, que a quienes "nos cabe el mundo en la cabeza" es a gentes como nosotros, pero que los no occidentales se conducen en sus vidas sólo con lo que les rodea. Esto me hace pensar fuertemente en un ejercicio que Michael Taussig hizo con un indígena ingano del Putumayo en Colombia. Taussig lo invitó a conocer el Cuzco, una vez en el majestuoso lugar el antropólogo le preguntó qué opinaba de todo eso: "Sólo para ricos", me dijo flemático. "Aquí no había pobres. Estas casas eran para los ricos". Hizo una pausa. "Lo he visto antes", añadió en forma casual. "Estas montañas. Estas piedras. Exactamente igual. Varias veces”. "¿Qué diablos quieres decir? No sólo sentí incredulidad, sino también desilusión. ¿No había hecho yo un increíble esfuerzo para traerlo a este lugar extraordinario, descubierto sino por Colón, al menos por Hiram Bingham, e inmortalizado por grandes poetas como Pablo Neruda en su poema épico, Alturas de Machu Picchu?", (Taussig 1995: 58). Pero al ingano le daba igual Colón, ni sabía quién era Bingham, y menos aún Neruda, sin embargo "conocía ya el lugar": "Sí, cuando curaba con yagé, me contaba el viejo indio del Putumayo, lo vi todo entonces, estas piedras, estos peñascos [...] Qué maravilla, pensé; en los lejanos bosques bajos en los que habitaba, el anciano estaba capacitado para ver este lugar [...] por medio de una percepción mística [...]" (Op. cit: 59-60). Lo que nos interesa extraer de de esta cita, es la idea sobre el conocimiento del "más allá" que el entorno mismo donde vive el indígena, esos múltiples mecanismos para acceder al mundo. Así que aquello de "pensar globalmente y actuar localmente" no es, como se piensa en los discursos contemporáneos, un asunto de receta occidental, es un asunto que todos nosotros y "ellos" hemos practicado y quizá también sabido antes de que las modas llegaran.

"Buscan sólo lo que de lejos o de cerca se vea conservado", dice un nativo de Saint Antonin Noble Val en el sur de Francia, refiriéndose a lo que buscan los ingleses, holandeses y belgas cuando llegan a comprar tierras al sur de ese país. Pero a la pregunta de: "¿en sus países ellos no tienen tierras o paisajes conservados?", responde: "Mire, ahora con la Unión Europea nosotros sí sabemos cómo viven ellos allá, no hemos ido nunca, yo no he salido de esta región más que para ir a Toulouse y hace mucho tiempo, sólo estoy aquí, pero bueno, sabemos ahora, le digo que por lo 
que ha traído la Unión, que cosas hay en qué países [...]. Sabemos que en Inglaterra ya no tienen campo, ya no hay campiña, todo está en manos de los que compraron antes, lo que los rodea ya tiene dueño y por eso para ellos lo lejos que somos nosotros está más cerca, más acá de ellos \{porque pueden acceder a ello\}" (entrevista en trabajo de campo 2006).

La imagen de una Unión Europea como la objetivación en un ser es constante entre los nativos rurales del sur de Francia, y aunque "lo" ven como el mediador entre el mundo - lo global- y lo que les rodea, es el pretexto que utilizan los entrevistados más letrados, pero en general tienen variadas formas de explicar de dónde viene la información de cómo viven "los otros". Una colega francesa en el trabajo de campo me decía: "Desde luego, aquí la gente sabe de qué te habla, no son como los rurales españoles que muchos son supersticiosos y quizá analfabetos, la gente de aquí es diferente [...]". Esa diferencia que pretendía señalar mi colega estaba asentada en el interés de marcar a como diera lugar que cualquier explicación sobre el "cómo viven y son los otros" no pasaba en ningún caso por otro mecanismo que el conocimiento "objetivo" de las cosas. Es decir que a los "míos sí les cabe el mundo en la cabeza", pero a los "otros no". No obstante, gracias al poder que me daba la mirada lejana como investigadora no nativa, lo que me dejaba entrever, tanto las entrevistas como la postura de mi colega era entre otras cosas, lo que he dicho al principio de este apartado sobre que pensamos casi siempre que a quienes "nos cabe el mundo en la cabeza" es a gentes como nosotros.

Pero entre los "paisas" se da un caso bastante particular sobre la manera de pensar "el mundo" como referente para practicar el entorno. Para estos habitantes, el mundo es "su" mundo. Es decir, no es posible que haya algo distinto, ni más importante a lo que ellos son o les rodea, ese es el mundo. Para un "paisa" todo lo demás es "inferior", el mundo sin ellos no podría existir, estaría inconcluso y sería un sinsentido. Durante los seis años de trabajo de campo que realicé entre ellos a través de distintos temas, pude evidenciar cómo quedaba ampliamente saldado aquel debate tan añejo de la antropología sobre la distinción entre si es la naturaleza la que moldea a la cultura o ésta la que moldea a la naturaleza: son los "paisas" — según ellos- como modelo de hombre (en el sentido amplio de la palabra) quienes dan origen al mundo, quienes lo hacen vivir y significar. En un trabajo de campo en el verano del año 2000, un habitante del pueblo de Aguadas (Caldas en Colombia) me decía: "No me pregunte por los indios que aquí vivieron, eso no importa; es más, no creo que existieran, pregúnteme por la zarzuela que se ofrecía aquí hasta hace pocos años, pregúnteme por la fuente del parque que la trajimos de París, o por el lago parecido a los paisajes de Venecia en el que muchos de nosotros nos enamoramos, tenía 
ese lago góndolas y todo lo demás, porque lo habíamos copiado tal cual en Venecia [...]" (entrevista en trabajo de campo 2004).

Para la cultura "paisa" la inclusión del mundo como "su" mundo, donde el entorno y el mundo es uno solo en sentido estricto, es manejado a través de distintas pedagogías sociales tales como: el nombramiento de lugares, el origen de ellos que asumen nacieron de Antioquia (capital Medellín) y no tienen más ascendientes que los judíos (sefarditas ${ }^{2}$ ), catalanes y vascos. La idea de alejarse de cualquier origen indígena y acercarse al "ser judío" ha calado de tal forma que hasta un Presidente de la República defendía dicha idea como beneficiosa hasta para la economía. Para lo cual se apoya en el siguiente texto publicado por el periódico colombiano El Tiempo (6 de octubre de 1931): "[...] el profesor Millward \{Russell Hasting Millward\} dice que en Colombia encontró una tribu con dos millones de habitantes y llevan el nombre de antioqueños. Este nombre dice, se deriva de la ciudad bíblica de Antioquía. La tribu tiene muchas palabras que parecen venir del hebreo [...]" (Jaramillo Salazar y Grupo de Investigación Territorialidades 2004: 66). Al respecto, el entonces diputado y luego Presidente de la República Alberto Lleras Camargo argüía con relación al texto: "Esta noticia está destinada a tener un éxito sin precedentes [...] y de propagarse tan sensacional descubrimiento pueden suceder dos cosas: o sube el crédito antioqueño, al asegurarse los banqueros de Wall Street de que sí son realmente judíos los habitantes de Antioquia, o baja, al [pensarse] que son una tribu salvaje" (Op. cit.: 68).

Con estos discursos, que como veremos más adelante sirven para dar supremacía en varios órdenes a la representación de lo "paisa", se presenta la figura de la "finca" (casa con parcela y su medio natural), del entorno y de "lo que hay que colonizar" como el mundo; en una palabra: "todo el mundo es paisa". Con gran diferencia, y que remitiría a otros análisis que aquí no se harán, pero que vale bien la pena referenciar, los momentos "gloriosos" del narcotráfico de algunos de los "paisas" de Antioquia contenían en mucho estos discursos.

Los campesinos y yanaconas tienen como marco de referencia para su distinción entre "el mundo" y "el entorno", los modelos de construcción de la persona y, con ello, características que van desde lo que ellos no son para ubicar a los otros, hasta ejercicios intelectuales que correlacionan tipos afines de identidades según roles o prácticas sociales, culturales y polí-

\footnotetext{
${ }^{2}$ Aunque los judíos sefarditas llegan tardíamente a esta región, y aunque no haya mayor indicio material de que los paisas desciendan de éstos, la proclama se hace por la apropiación de algunos de los valores que se atribuyen a estos judíos, tales como: ser buenos comerciantes, ponderar lo económico sobre otras dimensiones culturales y preservar la familia y la religión.
} 
ticas. Entre estos pobladores, el mundo puede ser una definición básicamente teórica que se utiliza, así como un ejercicio pedagógico para ubicar a personas, plantas, animales o lugares.

Lo que podemos decir al concluir este apartado es que finalmente las acepciones y diferencias entre "mundo" y "entorno" constituyen un sistema como medio para el conocimiento que generan a través de las categorías que componen dicho sistema y por las que a su vez son generadas, y, como medio para la práctica social en la que se ponen de manifiesto y cobran significado. Desde esta perspectiva, la idea no es tratar los conceptos de "mundo" y de "entorno" como un sistema de reglas inconscientes que hacen a los individuos y colectividades dar orden a lo sensible, sino situar como centro los contextos en los cuales se producen dichos conceptos y la dinámica que a través de los mismos generan los grupos sociales que los definen y viven. La posición de contexto es relevante por cuanto la definición y contenido de las clasificaciones y categorías de "mundo" y "entorno" pueden no sólo tender a mantenerse, sino también a cambiar, introducir o desaparecer elementos, según sean articuladas en las dinámicas socioculturales.

\section{TERRITORIALIDADES Y COSMOVISIONES}

Considero que para que "algo" pueda ser llamado "territorio" requiere de dos procesos que se dan simultáneamente y se renuevan, re-inventan o actualizan, según sea el caso: la territorialidad y la territorialización. Llamo "territorialidad" a la producción de territorio. Esta producción se materializa indudablemente a través de diferentes dimensiones de la cultura, tales como: la economía, la política, la religión y hasta la lúdica. Los ejercicios que producen territorios están mediados igualmente por las cosmovisiones, por la filosofía y por la visión del mundo que se tiene de manera individual y colectiva. Por su parte, la territorialización es la representación de los límites, de la acotación, de las fronteras, pero también del lugar mismo donde las culturas sitúan discursiva y prácticamente a las cosas y a los seres.

Tal como sucede entre los inuits (Collignon 1996), para los campesinos y yanaconas el territorio es concebido como un conjunto de relaciones: relaciones entre los lugares y los itinerarios recorridos para acceder a ellos, relaciones entre las formas naturales y los usos sociales. Los lugares, los sitios naturales y los campos no son identificados por ellos mismos, independientemente de sus relaciones materiales o imaginarias que condicionan las prácticas territoriales.

Pero no siempre esos sentidos se establecen en la propia cultura de referencia; también se dan en circunstancias de movilidad y migración poblacional. Este es el caso de los europeos del norte que emigran hacia el sur 
de Europa. Especialmente, los británicos asumen esos sentidos de pertenencia del lugar a donde llegan (al sur de Francia en su mayoría) por medio de la compra del patrimonio local (casas, edificios, villages...), lo que según ellos permite un sentido de pertenencia para instalarse y adaptarse al territorio de llegada.

\section{Producción de territorio en "el norte"}

Encontrar una "arquitectura con carácter" o cualquier bien inmobiliario que constituya patrimonio local, es la forma a partir de la cual un británico, holandés o belga que llega al sur del Francia, en nuestro caso, a Saint Antonin Noble Val, construye territorio. Es llamada arquitectura "con carácter" toda construcción en piedra antigua, con aspecto derruido y que da la idea de añejo. No importa si la construcción está en ruinas, es el significado de lo "ancestral" lo que importa. Frente a esta apropiación cada vez más pronunciada por los inmigrantes del norte — de Europa-, en el sur — de Europa- no hay una real resistencia de los nativos (de origen o por adopción); aparentemente todo es visto como parte de las nuevas territorialidades que se van produciendo en los contextos de la globalización y de los derechos de circulación de bienes y personas que da la figura de la Unión Europea. Las jóvenes generaciones que en mucho han heredado ese tipo de arquitectura y de patrimonio, prefieren ganar el doble, es decir, entregar a buen precio los bienes locales y lanzarse a una nueva producción de territorio a través de la construcción de casas más modernas, más cómodas y menos costosas, o también comprar en las opciones que se ven de más a más: les lotissements.

Otro de los aspectos que hay que resaltar es cómo la producción de territorialidad a través de la compra de viviendas, en especial por parte de los británicos, ha matizado la marcada segregación socio-espacial que había en los pueblos, particularmente en las Gargantas del Aveyron. En Saint Antonin Noble Val, los barrios estaban fuertemente marcados por la actividad o por el poder adquisitivo. Esto, en la actualidad, ha ido cambiando notablemente, puesto que los británicos compran aquí y allá, y entre más "enjundia" tenga un sector, más lo habitan. Lo cual crea un efecto trasversal a la producción de territorio, donde la condición de un barrio, que tiene población económicamente rica o pobre, queda en la actualidad en un plano secundario. La visión territorial del pueblo es entonces más horizontal que vertical, aunque claro, se puede pensar que al ser comprado por los británicos todo pasa quizá a ser de la elite, en el sentido tradicional del término, pero no, quienes compran también son gentes con poco dinero que han vendido todo en sus territorios de origen para comprar una casa con carác- 
ter en el sur de Francia. Este acceso, sin reparar en "la clase" por parte de los británicos, les ha dado un cierto derecho tácito a transformar muchas de las viviendas al estilo inglés, sin que por parte de los franceses haya mayor reparo: colores azules en puertas y ventanas, ventanas floridas y sin reparar en adornos, entre otras cosas, hacen de varias de las viviendas una postal inglesa en campo francés.

Por su parte, en el caso español la territorialidad de una apropiación "moderna" del entorno la da la preferencia por las residencias nuevas en parcelaciones de la periferia del pueblo o la ciudad. Si esto es lo que prefieren los nativos porque hacen mucho han dejado "los lejanos pueblos al monte", los neorrurales de las inmediaciones de La Torre del Bierzo, por el contrario, se apropian con "arraigo de la naturaleza" de ese monte olvidado. No obstante, esta forma de territorialidad no es propia, es decir, los extranjeros que se han instalado en Matavenero y Poibueno, por ejemplo, no pueden, según la administración municipal de la Torre del Bierzo, apropiarse jurídicamente de esas tierras. Sin embargo, esta suerte de transacción de territorialidad da ganancias a unos y a otros. Según se pudo constatar en el trabajo de campo, una vez recuperado el pueblo en cuestión, éste comienza a aparecer en el sistema jurídico a través de la Junta de Vecinos y en el sistema cartográfico, pues comienza a situarse en la cartografía regional y local, lo que es importante para la memoria colectiva de quienes un día por distintas causas abandonaron esos lugares. Y de paso, los "llegados" disfrutan no sólo del entorno, sino también de los beneficios económicos que reciben, entre otros medios, por conservación ecológica, cotos de caza y de las torres de energía eólica. A pesar de las ganancias mutuas, es necesario aclarar que la transacción de territorialidad sólo es posible entre europeos de la "Europa de los 15", de los 15 países que comenzaron formando parte de la Unión Europea ${ }^{3}$.

\section{Entre "lo bravo" y "lo manso"}

Como hemos anotado anteriormente, entre los campesinos y yanaconas lo bravo alude a la idea de mundo, de "lo que está allá", lo que es necesario referenciar para entender y hasta practicar su entorno. Sin embargo, "lo bravo" no sólo son sitios y lugares, también es una categoría mediante la cual se confiere a personas, situaciones, divinidades, sustancias corporales (como la sangre, por ejemplo) y hechos. Pero la idea de "lo que está allá", no significa que deba pensarse en lugares extranjeros o en seres y cosas extrañas del todo a la cultura local. Ese más allá no se concibe como parte

\footnotetext{
${ }^{3}$ Para mayor ampliación ver: Nates Cruz y Raymond (2007).
} 
del entorno asequible de manera directa, pues se necesitan rituales de intermediación o discursos formales de todo orden para poder hacerse a "lo bravo".

Lo bravo implica, en la idea de "mundo", una gran variedad de clasificaciones, pero para efectos de este artículo solamente haré alusión a la relación con la producción de territorio ${ }^{4}$. Lo bravo son las lagunas, páramos y bosques considerados sagrados y a los que acceden tewuas y cazadores, pero difícilmente gente del común. Sin embargo, desde las realidades sociopolíticas actuales, lo bravo también son hoy ciertos tramos de las carreteras a determinadas horas. A estos tramos se los denomina las curvas y buecadas. Son sitios vistos como trincheras de las guerrillas, como asientos de paso de los paramilitares o como sitios de encuentro entre los negociantes de látex de amapola; todo según la ubicación de esos sitios en determinadas carreteras del Macizo Colombiano. Como puede notarse, pensar en una carretera y en cada una de sus partes remite materialmente a lo que está "allî", "aquí" y no "allá". Esa es la complejidad de la denominación de "el mundo" como "lo bravo", no es que haya que tomar necesariamente distancia física, es la ubicación cultural y simbólica la que denomina esos lugares como "bravos", son sus prácticas, son sus discursos.

Ese mundo lejano es apropiable y para ello se debe "amansar", es decir, humanizar, hacerse culturalmente suyo, para que se convierta así en el entorno. El amanse es una categoría territorial, pero en concordancia con lo que implica la categoría de "lo bravo", alude a seres, cosas y hechos. Por ello lo dividen en cuatro tipos de prácticas: "amasar calmando", "amansar curando", "amansar limpiando" y "amansar poblando". Calmar es una práctica que "amansa" temporalmente "lo bravo", los chamanes y cazadores, por ejemplo, y si es del caso, los propios antropólogos cuando visitan lagunas y bosques considerados bravos, requieren de ceremonias o rituales mediante los cuales se logra simbólicamente el acceso. Con curar y limpiar se hace referencia fundamentalmente a poner sahumerios $\mathrm{u}$ ofrecer ofrendas en determinados lugares y sitios señalados en las carreteras para poder transitar sin peligro. Limpiar también es una práctica que puede aplicarse a la entrada de lagunas, bosques y páramos, pero bajo una ceremonia muy concreta, "los pagamentos", que consiste en beber constantemente una bebida preparada por el tewua y detenerse con él en sitios que considera claves para ofrendar plantas y granos de maíz a los dioses, y saludarlos con música de flauta durante todo el camino antes de llegar al lugar.

Amansar para poblar es un proceso de territorialidad que ha implicado desterritorializar simbólica y míticamente algunos lugares para apropiárse-

\footnotetext{
${ }^{4}$ Para mayor ampliación ver: Nates Cruz (2000).
} 
los. Los territorios apropiados son los antiguos pueblos de indios (como se denominaban en la Colonia), hoy convertidos en resguardos (reservas) o municipios. Así, los nativos comienzan haciendo alusión a "los tiempos de antes", a partir de cuya fórmula se narran mitos de fundación de los pueblos que habitan en la actualidad. Estos mitos les han servido para desterritorializar y re-territorializar: en la actualidad, la historia de la Conquista y la Colonia no es contada en las escuelas más que para señalar la opresión y marginalidad a que fueron sometidos, y lo que realmente cuenta en la historia de fundación es lo que ellos llaman "la fundación de los remanecidos". Son llamados "remanecidos" los santos y Vírgenes (figuras de no más de $50 \mathrm{~cm}$ ) que los misioneros dejaban enterrados en bosques o lugares selváticos para cristianizar el lugar y que de alguna manera en trabajos agrícolas alguno de los nativos encuentra y lleva a su poblado como el "hallazgo de un Dios de los antepasados". Ese hecho ha des-encadenado narraciones de similar composición a la de otros territorios del mundo hispano: los santos se mueven, pesan y casi hablan indicando el lugar donde quieren que se les deje con capilla o iglesia construida. Lo singular es la utilización de esas narraciones. Una vez el mito va de boca en boca, se fortalece por los líderes intelectuales y políticos para indicar cómo son "los remanecidos" los fundadores legítimos de sus poblados, y es a ellos a quienes se debe que el lugar exista amansado (habitado y cultivado) como está en la actualidad.

Pero también se amansa con maíz. El maíz junto a los "remanecidos" es otro de los símbolos fuertes de la territorialidad yanacona. Sembrando maíz se consolida una casa recién fundada, con el maíz se limpia en los pagamentos, el maíz es la moneda de intercambio en los trueques que aún existen.

Para los "paisas", por su parte, "abrir el monte" es lo que permite de entrada producir territorio. Veamos a continuación cómo viven y asumen estos procesos.

\section{Colonizadores y colonizados}

Los "paisas" habitantes del centro de Colombia, entre los departamentos de Antioquia, Caldas, Risaralda, Quindío y norte del Valle del Cauca, son vistos por el resto de los colombianos como "colonizadores" y como "berracos", término cuyo uso social alude a "aguerrido", "valiente". Pero ellos mismos también se autodenominan con la segunda categoría. Los colonizadores por excelencia de todo este grupo son los "paisas" de Antioquia quienes detentan lo que se ha llamado en Colombia la Colonización antioqueña, animada por varias disposiciones jurídicas, comenzando por la ley de ocupación de tierras del 13 de octubre de 1821, por la ley 31 de 1823 sobre 
"apertura de caminos", por el decreto del 27 de mayo de 1842 en el que se estipula el derecho a casa y labranza (incipiente configuración de la finca) y, finalmente, por la ley 61 de 1874 de los Estados Unidos de Colombia, con la estipulación del derecho a habitar tierras sin medida de extensión, siempre y cuando fuesen habitadas y cultivadas.

Los "paisas" de Antioquia se consideran y son considerados por los demás "paisas" como los "verdaderos paisas". Los de Caldas (capital Manizales), de Risaralda (capital Pereira) y del Quindío (capital Armenia), son los colonizados.

Las imágenes de hombres y mujeres aventureros y aguerridos, labriegos y agricultores que llegan a selvas vírgenes, a bosques "antes nunca habitados" y que a partir de allí civilizan, son muy usuales, tanto en los discursos de la gente del común, como en los de los intelectuales, que por cierto se presentan como historiadores, los cuales abundan en cada pueblo y son considerados ilustres defensores de la identidad y la verdadera historia paisa. Cuando se investiga en las crónicas de indias para saber si había habitantes en los lugares a donde llegaron los colonizadores "paisas" de Antioquia (nos referimos particularmente al hoy Caldas, Risaralda y Quindío), encontramos que los cronistas referencian grupos indígenas de los cuales saben su existencia "de oídas", porque muchas de esas tierras no entraron en la conquista española. No obstante, tanto los "paisas" letrados como iletrados asumen con vehemencia que eran tierras incultas, sin humano alguno. Lo que llama la atención es que efectivamente en todas las referencias oficiales del Estado se asume que eran "tierras sin gente", pero aunque no venga al caso explicar todo el proceso aquí, debo decir que en el proceso de investigación de cinco años en la región, hay bastantes elementos que llevan a pensar que "eran tierras con gente" de la cual nadie sabe cómo, ni dónde murieron. Lo que sí podemos decir es que curiosamente para algunos de aquellos historiadores locales, "los indios que allí vivían murieron de pestes justo antes de que los colonizadores de Antioquia llegaran [...]" (entrevista de trabajo de campo 2004).

La colonización de las tierras del sur (hoy Caldas, Risaralda y Quindío) por parte de los paisas de Antioquia es agradecida y venerada por quienes en las tierras conquistadas se consideran "sus colonizados". Si pensamos en que allí "no había nadie", efectivamente los caldenses, risaraldenses y quindianos colonizados son sus descendientes: "Somos los colonizados de Antioquia, Antioquia es nuestra Matria, somos sus hijos descendientes [...]" (entrevista en trabajo de campo 2005).

Esos aventureros aguerridos llegaron en oleadas que son narradas, tanto en lo escrito como en lo oral, a través de cinco momentos que marcan la territorialidad de la región y la "traída de mundo" a las tierras del sur. La 
narración de la primera figura muestra a desposeídos antioqueños buscando tierras incultas. La segunda, a grupos que llegan tumbando monte y asentándose temporalmente en sitios estratégicos en lo agrícola. La tercera de las figuras narra cómo estos grupos regresan a vender o intercambiar el producto de las cosechas para adquirir herramientas y propiciar a sus familias mejores condiciones en los ranchos de las nuevas fundaciones. La cuarta los presenta como fundadores de pueblos, personajes que encuentran "el lugar prometido", esto es, territorializar a través de una zonificación que permitiera repartirla a las familias incluyendo los cultivos comunales, para luego instaurar la organización jurídica y social teniendo las fincas (recordar el sentido ya descrito) como centro de congregación y de identidad cultural y territorial. La quinta y última figura habla de cómo con la seguridad que daba la zonificación y la organización socio-jurídica alrededor de la finca, erigen finalmente un municipio o parroquia. Así, la zonificación fue repartida entre sementeras y rozas con cultivos de pan coger (maíz, fríjol, plátano y caña de azúcar, principalmente) (De los Ríos 1981; Nates Cruz 2007).

De todas esas imágenes interesa aquí sobre todo la figura de la finca. Éste es el medio por excelencia para crear territorio. Siendo los "paisas" fundamentalmente rurales, la finca es lo que les apalanca asentamientos definitivos y lo que les asegura haberse "apoderado" de un determinado lugar. Pero es importante tener en cuenta que ese empoderamiento funge, tanto en el sentido literal de tener una finca, como en la idea de manejar el entorno (social, físico, rural y urbano) y de concebir y administrar una finca.

En la instauración de la Colonización antioqueña, la finca da a los colonizadores sustento económico. Además, les da una cohesión social a través de una suerte de pluricomunalidad que les permitía proyectar, con la expansión de las fronteras de Antioquia, su abolengo construido a partir del tan defendido por ellos, origen judío y español (catalán y vasco), que no pasaba a los nuevos descendientes de las tierras colonizadas, pues éstos serían "paisas" y con ello era suficiente. La finca también era el medio de cohesión familiar que se capitalizaba en la producción económica donde todos aportaban a un bien común ostentado por los hombres, pero en el fondo manejado por las mujeres llamadas "matronas", a la imagen de la "mamma" italiana. Es una sociedad donde la mujer es la que se reivindica como jefe del hogar. En la contemporaneidad la finca constituye la base del sistema socio-económico mediante el cual se puede dimensionar lo que promulgan fácilmente en los pueblos: "la finca es el primer eslabón del progreso y la pujanza de una raza". En el resto de Colombia esta idea calaba como una idea romántica del prototipo de civilización rural al que se debía (y aún en la actualidad) tender.

La fuerza de la economía en la finca la daba hasta los años 90 el culti- 
vo del café. La estrecha relación entre la finca y el cultivo del café, implicaba que ésta debía soportar pérdidas y ganancias en todo sentido. Por ello, la crisis del café que comienza en el año 1987 con la caída del precio y que se agudiza avanzados los años 90, trae como consecuencia la inmigración de un número considerable de pobladores que buscan países como España, Francia y Estados Unidos para instalarse, lo cual produce el abandono paulatino de varias de las fincas, tanto en el sentido de cosmización, como en el sentido de medio material de producción. En la actualidad, algunas han sido alquiladas para que sean cultivadas por terceros, o para ser habitadas o convertidas en hoteles ecoturísticos, donde se capitalizan al máximo las narraciones superlativizadas de la Colonización Antioqueña, o simplemente son utilizadas como casas de campo. De alguna manera, la arquitectura antioqueña, y las plantaciones de café, son en gran medida un decorado de la "venta de historias".

Existe otra figura territorial que nombramos brevemente, debido a la extensión de este artículo: la fonda. Ésta es una especie de posada con la que siempre se ha identificado al "paisa" y en la cual se apoya la Colonización antioqueña, pero también posterior a este proceso, la fonda permite congregar socialmente a los habitantes de los pueblos fundados. En la actualidad es muy corriente encontrar fondas en las ciudades y pueblos, pero con otro uso, el del bar al que se va de "tomata" y de baile. En las ferias y fiestas rituales de pueblos y ciudades paisas, las fondas se recrean en el sentido ancestral como una forma de revivir los momentos de la Colonización antioqueña y de proclamar el origen antioqueño de los territorios colonizados.

\section{LA TERRITORIALIZACIÓN DEL CUERPO}

Entre los "paisas" la territorialización del cuerpo explicita imágenes de la Colonización antioqueña: el arriero, el cacharrero, el indígena. Pero también entre los que no son "paisas" existe tal explicitación, para ubicar las imágenes en lugares bien definidos: las dos primeras en lo rural inhóspito y hasta lo legendario; la tercera imagen en lo inculto, donde alguna vez existieron, pero como se ha mostrado al llegar, no quedaba más que monte.

Confinada la figura de lo indio al plano del folclor, a menudo se presentan mitos y leyendas donde aparece la figura del indio con plumas y tocados, desnudo y pintado el cuerpo como los indígenas amazónicos, apropiándoselo como el "Cacique Pipintá". Es decir, si existieron indígenas en la región que los antecedieron, éstos debieron ser seguramente "de elite" y, además, con toda la parafernalia de la idealización de un indio, tal como se enseña en las escuelas. Los que no son "paisas" están por ahí, no im- 
porta dónde, porque lo que realmente importa y existe en Colombia desde la supremacía del discurso paisa de los antioqueños y de sus herederos, está en el "país paisa" donde personajes míticos como "el berraco de Aguadas" o "Putas de Aguadas" son héroes que encarnan y definen lo "realmente paisa", en oposición a otros que no tendrían relaciones directas con el legado de tales héroes legendarios traídos de la Colonización antioqueña. Éstos tienen una relación de contigüidad espacial, tanto de ubicación como de adaptación en los discursos cotidianos y míticos de lo que se proyecta ser, un paisa real.

El nombramiento a través de los apellidos, también es otro de los recursos frecuentes en el mundo contemporáneo para asumirse desde el origen antioqueño. El nombramiento, las procedencias, los acentos y un prototipo blanco con todas sus caracterizaciones físicas, redundan en las definiciones de lo culto y lo paisa. Los lazos de parentesco que geográficamente tienden a localizarse en las poblaciones cercanas del norte de Caldas como los enclaves de la Colonización antioqueña: los poblados de Aguadas, Salamina y Neira, son vistos como la fuente de transmisión de lo que se considera verdadero "paisa".

Por su parte, y según lo expuesto, los yanaconas definen y ubican a los seres desde lo físico y lo metafísico. Los mundos bravos albergan una gama de poblaciones que a primera vista no podrían estar en el mismo lugar, pero que si tomamos en cuenta que esta determinación obedece a características culturales y sociales, más que a lugares geográficos en sí, la lógica es evidente. Tapuncos, aucas, ánimas, gringos, españoles, guerrillas, paramilitares, indígenas amazónicos y compautos o empautaos, son sus "habitantes".

Atendiendo a la anterior clasificación local, los habitantes de estos mundos se podrían clasificar en: el "Mundo de los Antepasados" (tapuncos), el "Mundo de los Muertos" (aucas y ánimas) y el "Mundo de los A-normales" (gringos, españoles de la Conquista y por derivación los actuales, guerrilla, paramilitares, indígenas amazónicos, compautos o empautaos). El Mundo de los Antepasados es el mundo que los nativos ubican debajo del suelo, donde van los antepasados o tapuncos. Los distintos significados que contiene el concepto tapuncos incluye a los aborígenes que huyeron de los españoles, quienes perteneciendo al pasado viven siempre en un tiempo cronológico presente (nunca envejecerán, y estarán bajo el suelo esperando a que el mundo de los humanos actuales se vuelva al revés, que cambie de sentido, y "lo de debajo" pase a estar "arriba", para volver a posesionarse del territorio del que fueron expulsados por la Conquista española). También incluye a los seres que se alimentan del olor de las comidas porque carecen de ano y son considerados, además, los primeros cultivadores de maíz. Este Mundo de los Antepasados es concebido como el "mundo de los muertos 
buenos". Así, el mundo de los antepasados perteneciente a un tiempo pretérito, es la fuente del futuro cuando su mundo "de abajo" cambie de sentido.

El Mundo de los Muertos es un mundo que comprende a los aucas y las ánimas. Este mundo plantea una categoría de seres "realmente muertos": personas de mal vivir o de fallecimiento en circunstancias sancionadas negativamente. De ahí que estos mundos sean descritos como "mundos oscuros", sugiriendo un olvido, una muerte en la memoria. Son considerados aucas los niños que mueren sin bautizar entre el momento del nacimiento y un año de edad. Pero el bautizo no supone necesariamente el rito oficial católico, ya que un niño queda bautizado si una persona adulta diferente del padre o la madre, pone agua sobre la cabeza de éste al momento de nacer. Las ánimas son adultos muertos de forma o en estado sancionado negativamente: personas que han fallecido por asesinato, suicidio y las mujeres mayores de cuarenta años que mueren sin tener hijos. Esto es, quien no cumple su ciclo de vida por suicidio, muerte súbita e infertilidad.

El Mundo de los A-normales es el mundo de los seres humanos vivos que habitan en el límite de su cultura. Gentes que, según los campesinos y yanaconas, "viven mal". Es decir, viven fuera de la norma cultural, de las conductas apropiadas para ser aceptado como una persona normal entre estos campesinos e indígenas. La clasificación remite a las categorías locales de "el Mundo de la gente del monte" (gringos, españoles, indígenas amazónicos, guerrilla y paramilitares) y "el Mundo de los compautos o empautaos". El Mundo de la gente del monte, al igual que los otros mundos descritos, tiene una ubicación en la geografía: la selva, los bosques y los cerros, cuyo conjunto se denomina localmente "el monte". Este espacio lo presentan como un lugar confuso donde no es claro discernir entre el día y la noche, un lugar donde habitan los "extraños". Es decir, que tienen un modo de vida totalmente diferente al de un comunero normal. La concepción y presentación del Mundo de la gente del monte muestra las fronteras de la humanidad. El reconocimiento de la humanidad del "otro" con respecto a un campesino o yanacona está en la medida en que se comporte como un nativo. Son figuras entre sí familiares, pero esta familiaridad no significa que los nativos ignoren la real diferencia que hay entre ellos. El comportamiento de la gente del monte está caracterizado por actividades sociales prohibidas tales como el robo, el saqueo, el engaño, el aislamiento, el nomadismo y los lazos de parentesco que les resulten confusos como la poligamia, la poliandria, el incesto, etc. Los habitantes de este mundo no sólo se comportan de manera distinta a un nativo, sino que tienen una apariencia personal también distinta.

Aunque hay un espacio geográfico estereotipado que ocupa el Mundo de la gente del monte, cuando se presenta a cada uno de los grupos que lo 
componen, se los ubica en contextos concretos diferentes. De los indígenas selváticos y de los guerrilleros, se tienen referencias directas, pero en muchas de las narraciones se adornan con invenciones que legitiman aún más su pertenencia al mundo liminal. De los españoles y de los gringos, en los que incluyen a todo extranjero que no habla castellano, los nativos saben que han transitado por diversos motivos en la región, pero no se sabe de dónde vienen, ni cómo es el lugar donde viven; no se tiene un referente tangible de su procedencia, ni de su cultura. Así que, como referencia de origen, sólo está la recreación que se mantiene en la tradición oral que testimonian los inmigrantes, los medios de comunicación y las descripciones que de estos grupos suelen hacer los gringos y españoles actuales que algunas veces visitan la región para hacer turismo por las lagunas, parques arqueológicos y naturales.

Los indígenas amazónicos de este mundo bravo son descritos bajo la influencia de las imágenes que sobre éstos tiene la mayoría de la población mestiza colombiana. Esta influencia se puede ver en las descripciones que se hacen de dichos indígenas, bajo los epítetos de incivilizado y salvaje, usados por algunos mestizos. En las narraciones, estos epítetos aparecen mezclados entre el presente y el pasado, teniendo como referente una "actualidad civilizada" (donde viven los indígenas andinos y los mestizos urbanos) y un "ayer salvaje" (donde viven los indígenas amazónicos).

En el Mundo de los compautos o empautaos se considera que sólo viven éstos, los cuales son definidos como personas malditas, pero que a pesar de ello, viven dentro de las comunidades del Macizo. Se les atribuye pactos con el diablo llamado Jucas, al que se le piden poderes desmesurados o malignos. Estos personajes bien podrían llamarse brujos, pero hay una distinción de género: la mujer que establece el pacto será llamada bruja y el hombre, compauto. Sin embargo, en plural se refieren a este grupo como los compautos o empautaos. En la actualidad los nativos que se enriquecen "de la noche al día" con dinero que tácitamente viene de la venta de látex de amapola, son vistos también como compautos o empautados (Nates Cruz 2000).

Del otro lado, en el caso español estudiado y con relación a los europeos del norte, vale la pena resaltar dos clasificaciones. Primero, los neorrurales no españoles que a su vez son definidos como los "limpios" en el sentido ecológico del término, los "raros" y los "jipis". Los localizan geográficamente en la meseta rural alejados de las costas y se asume que éstos no se mezclan con los nativos. Y, segundo, los jubilados que son vistos como "buscasol" o "tienen perras", los cuales se ubican en las costas.

En el caso francés, para los europeos del norte, principalmente para los británicos, hay dos categorías definidas por el rol, el comportamiento, el lugar de origen y la época de inmigración: 1. "Les étrangers" que a su vez son 
clasificados en: a) los "inversores británicos", quienes habitan les villages totalmente rurales o propietarios de tierras y construcciones rurales a los alrededores de la cabecera municipal del pueblo. Esta categoría impone una marca social instaurando una forma de "territorio circulatorio", a través del mercado inmobiliario que han desarrollado entre europeos del norte, especialmente británicos. Este mercado permite vender y trasladarse a menudo de casa o de pueblo, rotar el territorio entre los mismos y alejar cada vez más a un francés de la posibilidad de acceder o comprar una vivienda en su propio territorio; b) las "familias de Europa del norte que buscan hacer su vida" y habitan la zona urbana del pueblo, c) los "voyous", llamados también los "signos de interrogación", se asume que viven en las márgenes del pueblo, pero también entreverados en el centro, d) los "Rmistes", británicos buscadores de la ayuda económica mínima de inserción -RMI- francés, se entiende que habitan en el vecindario de los voyous y las zonas rurales, e) los "thatcheristes", ingleses que salieron de Gran Bretaña durante el período de Margareth Thatcher, son gentes en general de escasos recursos que buscan instalarse en las partes más rurales o al menos allí se asume que viven. 2. "Les néo-ruraux non français" que a su vez se conciben a través de: a) los "soixante-buitards" o aquellos que llegaron con la ideología o tendencias del 68, b) los "antipodes" o los apuestos a la sociedad normalizada en cuanto a su "politesse". En la ubicación que dan los nativos a estos neorrurales no hay ni un lugar propio, ni una segregación socio-espacial, como sí sucede en el caso español.

La ubicación de neorrural, tanto para el caso español como francés, es una categoría con la que se dice se vivirá toda la vida, no necesariamente porque el detentador quiera serlo toda su vida, sino porque los nativos lo designarán como tal para siempre. Pero a pesar de lo dicho, existe un medio de "remediarlo", encontrar un reconocimiento del pueblo en un dominio intelectual o económico y marcharse a vivir fuera. Es decir, como una especie de reconversión socio-cultural y territorial.

\section{RETROSPECTIVAMENTE}

Lo que hemos visto acerca de cómo se piensa "el mundo" y se practica el entorno entre yanaconas, europeos del norte, franceses del sur, españoles del Bierzo o "paisas" del centro de Colombia, podría quizá de manera desprevenida ubicarse en posturas clásicas de la antropología. En este sentido, cabría pensar que la concepción y desarrollo del concepto de naturaleza esta directamente relacionado con que si la cultura ve el entorno como un todo integrado, o lo ordena bajo divisiones espaciales próximas o lejanas (Dwyer 1996). Por otra parte, pudiera pensarse que también aluden en 
sus discursos y prácticas al mundo y al entorno como "algo" material y espiritual que se deriva solamente del conocimiento y de la comprensión (Howell 1996). O que se está hablando de una comprensión de la naturaleza como una categoría de objetos y como una esencia interior (Ellen 1996). Pero también podría pensarse que hay en todos los casos una visión intervencionista desde la cual las actividades humanas se consideran de cierta manera como parte misma del sistema (Coursey 1978).

Sin embargo, lo que he querido mostrar y demostrar dista de esas posturas en que en todos los casos estudiados, "pensar el mundo, practicar el entorno" es un proceso correlacional que muestra cómo se territorializa el conocimiento "de las cosas" y cómo a partir de allí se territorializa el cuerpo de esas cosas. Hablar de mundo y entorno permite categorizar y clasificar personas, saber cómo y desde dónde actuar con ellas o con respecto a ellas. Se hace lo mismo con los objetos, para saber qué son y cómo usarlos o ponerlos en alguna parte o simplemente saber que existen. Pero también con los discursos, para armar espacios sociales que congregan, estigmatizan o excluyen mediante la muerte social a "los otros" y en algunos casos a los "mismos".

A mi juicio, este sentido de acotar, de delimitar, de representarse a sí mismo, a los otros y aquello que les rodea, en otras palabras, este sentido de territorializar, conlleva, si no a la comprensión, sí a objetivar la diversidad intercultural e intracultural. Las estructuras de dicha comprensión y objetivación han coadyuvado a comprender en las culturas presentadas en este artículo, la dimensión de la realidad en cuanto a las relaciones institucionales y cotidianas de lo que hemos llamado "el mundo" y el "entorno". También con relación a las experiencias que viven estos grupos, hemos podido comprender desde la representación de la historia particular y colectiva, cómo se practica lo pensado y cómo se diseñan y materializan social y culturalmente las expresiones de lo que es "el mundo" y el "entorno.

\section{BiBLIOGRAFÍA CITADA}

Collignon, B. 1996. Les Inuit: ce qu'ils savent du territoire. París: L’Harmattan.

Coursey, D. G. 1978. "Some ideological considerations relating to tropical root crop production", en E. K. Fisk (ed.), The adaptation of traditional agriculture: socioeconomic problems of urbanization, Development Studies Centre Monograph 11. Canberra: The Australian National University.

De los Ríos, R. 1981. Orígenes y colonización hasta 1850. Manizales: Biblioteca de Escritores Caldenses.

Dwyer, P. D. 1996. "The Invention of Nature", en R. F. Ellen \& D. Fukui (eds.) Redefining nature: ecology, culture and domestication. Oxford: Berg.

Ellen, R. F. 1996. "The cognitive geometry of nature: a contextual approach", en G. Palsson y P. Descola (eds.), Nature and Society: anthropological perspectives. Londres y Nueva York: Routledge. 
Gutiérrez Estévez, M. 1988. Mito y ritual en América. Madrid: Alambra.

Howell, S. 1996. "Nature in culture and culture in nature? Chewong ideas of 'humans' and other species", en G. Palsson \& P. Descola (eds.), Nature and Society: anthropological perspectives. Londres y Nueva York: Routledge.

Jaramillo Salazar, P. y Grupo de Investigación Territorialidades. 2004. "El País (aje) de los Paisas: lo regional más allá de la Región”, en B. Nates Cruz y F. Villota Galeano (comp.), La desgeneralización del mundo. Reflexiones sobre procesos de globalización. Manizales: Universidad de Caldas.

Milton, K. 1993. "Introduction: Environmentalism and Anthropology", en K. Milton (ed.), Environmentalism: The View from Anthropology. Londres y New York: Routledge.

Milton, K. 1996. Environmentalism and cultural theory: exploring the role of anthropology in environmental discourse. Londres y Nueva York: Routledge.

Nates Cruz, B. 2000. De lo Bravo a lo manso. Territorio y Sociedad en los Andes (Macizo Colombiano). Quito: Editorial Abya-Yala.

Nates Cruz, B. (Comp.). 2006. Evocaciones míticas e identidades actualizadas. Región y dinámica territorial en la construcción del país paisa. Manizales: Universidad de Caldas.

Nates Cruz, B. y Raymond, S. 2007. Buscando la naturaleza. Migración y dinámicas rurales contemporáneas. Barcelona: Anthropos.

Taussig, M. 1995. Un gigante en convulsiones. El mundo humano como sistema nervioso en emergencia permanente. Barcelona: Gedisa.

Fecha de recepción: 16 de octubre de 2008

Fecha de aceptación: 23 de febrero de 2009 